REVISTA DE DERECHO UNED, NÚM. 17, 2015

\title{
LA TUTELA EFECTIVA DE LA CREACIÓN DE CONTENIDOS E-LEARNING: UNA SOLUCIÓN EN LAS EXCEPCIONES AL DERECHO DE AUTOR
}

\section{EFFECTIVE PROTECTION OF THE CREATION OF CONTENTS E-LEARNING: A SOLUTION IN THE EXCEPTIONS TO COPYRIGHT}

\section{FERNANDO LÓPEZ RODRÍGUEZ}

Doctorando E. T. S. Ingenieros Industriales de la UNED Departamento de Ingeniería Eléctrica, Electrónica y de Control Programa: «Derecho de las Nuevas Tecnologías de la Información y las Comunicaciones»

Dr. Juan Peire Arroba

Catedrático de Tecnología Electrónica

Dpto. de Ingeniería Eléctrica, Electrónica y de Control, ETSII de la UNED Doctor Ingeniero Industrial. Licenciado en Derecho Director del Centro Asociado de la UNED en Ávila

Resumen: La evolución de la tecnología ha llevado, necesariamente, a un desarrollo de los derechos de autor y de la Propiedad Intelectual. Estas evidencias se refieren a la relevancia por la puesta en funcionamiento de las plataformas tecnológicas en relación con sus contenidos contractuales, limitaciones, derechos fundamentales y conceptos de creación y autoría. De ahí, la necesidad de afrontar la tutela de los derechos de autor en las obras multimedia y, particularmente, los de los creadores de contenidos en plataformas e-learning, en la búsqueda de nuevos mecanismos jurídicos eficaces, o la readaptación de los existentes al espacio digital. Razón por la cual se plantean las importantes exigencias de un estudio sistematizado en torno a los aspectos jurídicos inmanentes de adaptación al derecho de pro- 
piedad intelectual, por la heterogeneidad de las conceptualizaciones que integran los elementos de e-learning y, consecuentemente, reconciliar el amparo de las TIC con excepciones al derecho de autor.

Abstract: The evolution of technology has led necessarily to a development of copyright and intellectual property. This evidence, refer to the relevance of the operation of technology platforms in relation to their contractual content, limitations, fundamental rights and concepts of creation and authorship. Hence, the need to address the protection of copyright in multimedia works and particularly the creators of content in e-learning platforms in the search for new effective legal mechanisms, or restructuring of existing space digital. Why, raised the important requirements of a systematic study environment immanent legal aspects of adaptation to IPR, the heterogeneity of the conceptualizations that integrate the elements of e-learning and consequently to reconcile the protection of the ICT s exceptions to copyright.

Palabras clave: Tecnología. Contenidos educativos. Autor. Tutela. Herramientas. Propiedad Intelectual. Plataformas. Aprendizaje a través de las TIC. LMS. CSS3. HTMLS5.

Keywords: Technology. Educational resources. Author. Tools. Guardianship. Intellectual Property. Platforms. E-learning. LMS. CSS3. HTMLS5.

Recepción original: 8/06/2015

Aceptación original: 13/07/2015

Sumario: I. Introducción. II. Procedimiento. III. E-Learning y empresa. III. 1. Comercialización E-Learning. III. 2. Perspectivas en las plataformas E-Learning. IV. Conclusiones.

\section{INTRODUCCIÓN}

En el espacio de la educación se implantó desde hace un tiempo, por razones obvias, la utilización de las TIC y el desarrollo de contenidos para estas plataformas digitales y sistemas de e-learning por parte del profesorado.

Hay que mencionar, además, el hecho generalizado de que esta función se conciba como algo inherente a la educadora e instructiva tarea del profesor, sin el reconocimiento de una autoría con todos los derechos morales y materiales que implica, por lo que lleva a la necesidad de una tutela efectiva. 
$\mathrm{Al}$ mismo tiempo, un estudio sistematizado en torno a los aspectos jurídicos inmanentes al autor y su condición en la red será la pretensión de este trabajo en relación con el desarrollo de la Tesis Doctoral en curso, en el Departamento de Ingeniería Eléctrica, Electrónica y Control, de la Escuela Superior de Ingenieros Industriales en la Universidad de Educación Nacional a Distancia y bajo la dirección del Dr. D. Juan Peire Arroba.

Consecuentemente, su estudio se establece en el ámbito de la Propiedad Intelectual, como ciencia para disponer la discusión de la hipótesis, y sus implicaciones en el desarrollo de la creación de contenidos en plataformas e-learning y el Derecho Laboral y las Tecnologías de la Información y las Comunicaciones.

Hecha esta salvedad, la formulación de la hipótesis se delimitará por el artículo 1 del Texto Refundido de la Ley de Propiedad Intelectual (TRLPI) en cuanto se refiere a que la propiedad intelectual corresponde al autor de la misma, sea científica, literaria o artística.

A este respecto, el derecho de autor, como fundamental, está llamado a la consecución de valores constitucionales unívocos y la manifestación de su creatividad personal, su capacidad y el deseo de originalidad son los atributos en los que se encastra la libertad de creación y, por lo tanto, el derecho de autor.

Por su parte, dice el profesor Davara sobre los derechos de Propiedad Intelectual: «Protegen todas aquellas creaciones del ser humano con un carácter literario, científico o artístico, expresados en un soporte tangible o intangible y son de carácter moral o patrimonial» ${ }^{1}$.

A su vez, el artículo 20,1 de la Constitución española, de 27 de diciembre de 1978, establece: «Se reconocen y protegen los derechos: [...] b) A la producción y creación literaria, artística, científica y técnica», supone un reconocimiento del libre ejercicio de la libertad en estos campos, como derecho fundamental y como derecho moral inalienable sobre las creaciones personales.

En el caso de que se considere la norma sobre el derecho de autor en su conjunto, hay un derecho primario en el autor de la obra frente a la explotación. Por tanto, esta última se ejercerá dentro de los pactos contractuales, que han de respetar el derecho moral del autor de la obra. Luego, dentro de esos pactos, cabrían múltiples fórmulas de retribución por los derechos respectivos.

${ }^{1}$ DAVARA RODRÍGUEZ, M. A. «Derecho Informático», Editorial Aranzadi, Pamplona, 1994, pág.73. 
Si bien es cierto que la creación de contenidos en las plataformas e-learning, por parte del autor, es fruto de su trabajo, en consecuencia se establece un derecho de propiedad intelectual, ya que la obra objeto de tal derecho adquiere una doble dimensión: material -corpus mechanicum-e intelectual -corpus mysticum-, con el reconocimiento de los expresados derechos.

De lo antedicho se infiere que el derecho de propiedad intelectual de los autores de contenidos en plataformas e-learning, como asalariados, necesita un estudio riguroso a través de los elementos constitutivos de las creaciones, que designan diferentes derechos subjetivos intelectuales de carácter espiritual a diferencia de los industriales y comerciales, a configurar en su protección el régimen de transmisión y dispositivo en cuanto a la capacidad del cesionario.

Pero es necesario resaltar también, desde una concepción iusprivatista, que el Derecho de Autor se asocia a una propiedad y, desde una concepción como Derecho humano, protege igualmente al autor de forma genérica, como al usuario en relación a sus derechos de acceso a las obras protegidas.

Al mismo tiempo, esta caracterización compleja del Derecho de Autor le concede una autonomía per se reconocida al normarlo como un derecho independiente, como se enuncia en el Texto Refundido de la Ley de Propiedad Intelectual y sus principios rectores. Conviene subrayar lo que el Tribunal Supremo en Sentencia del 2 de marzo de 1992, Sala de lo Civil (RJ 1992\1834) expuso².

Sin duda, el concepto de creación en la RED y sus derechos morales y materiales constituye la esencia de las relaciones laborales de los autores asalariados.

2 «(...) no cabe duda de que el derecho moral de autor, no recogido con esa expresión literal en ninguno de los textos citados, sí se desprende de su articulado, siendo pacífico hoy día que el derecho de autor es un derecho subjetivo, de carácter absoluto, con monopolio jurídico, temporalmente limitado y que no tiene exclusivamente naturaleza patrimonial o económica, pues junto a tal aspecto, tiene un contenido extrapatrimonial que no es otro que el derecho moral antes aludido, con facultades personalísimas, aunque no sea derecho de la personalidad por carecer de la nota indispensable de la esencialidad, al no ser consustancial o esencial a la persona, dado que no toda persona es autor; pero creada la obra de arte, no puede desconocerse su vocación o llamada a la exteriorización, aspecto material del derecho inmaterial que al autor asiste, de forma tal que en todo contrato en el que se tienda a la difusión de la obra creada ha de contemplarse ese doble aspecto patrimonial y espiritual o moral, comprendiendo éste la paternidad de la obra, su integridad, la reputación y buen nombre de su creador etc... en cuanto que jurídicamente las obras de la inteligencia son una derivación y emanación de la personalidad, aspecto en modo alguno negado por la vieja Ley aludida, ni por el CC.» (1992:1834). 
Teniendo en cuenta que el descubrimiento se dice que es el producto del esfuerzo creativo de la razón sobre el sustrato de la realidad y la creatividad humana implica un descubrimiento en el sentido de que en el acto creador se revelan aspectos de la realidad, entendida en sentido amplio, al hablar de descubrimiento se entiende que el objeto descubierto posee existencia per se, y no porque se le otorgase, y que dicha existencia es de algún modo tal que descubrir no sería más que poner de manifiesto algo que ya estaba ontológicamente presente en la realidad, es decir, perceptible por los sentidos o localizables espacial y temporalmente.

Aunado a la situación, la distinción entre creaciones asociadas a la manipulación de entidades físicas -las cuales pueden efectuarse con fines técnicos o artísticos (representaciones dramáticas o fílmicas)- y creaciones asociadas a la manipulación de entidades puramente intelectuales, no será válida totalmente si se sitúa en una perspectiva desde la cual toda creación, en tanto producto del quehacer humano, está asociada a un universo de significados que trasciende la materia que lo soporta, con la cual no puede agotarse en ella.

De igual modo que el acto de creación implica un descubrimiento, es preciso concentrarse en aquellos actos que involucran la creación de principios aplicables a la consecución de fines concernientes al quehacer humano (cognitivos, estéticos, etc.), y afronta la hipótesis según la cual el «yo» se manifiesta en lo creado, en sentido trascendental de Kant, en cuanto lo fenoménico de las cosas es lo primero que aparece en el nivel del conocimiento sensible.

Sin embargo, lo que se da en dicho nivel es una pluralidad dispersa de datos, que no es el objeto del conocimiento. El objeto hay que construirlo y darle forma, de ahí que, en Kant, el sujeto sea un sujeto unificador.

Para tal efecto, se necesita un puente de enlace entre la sensibilidad, facultad de percibir como la más originaria y de la que las intuiciones sensibles son la materia de conocimiento y sus formas puras $a$ priori, el espacio y el tiempo, y el entendimiento; y ese puente será la creación. En este sentido, esta actitud idealista se denomina trascendente.

Por su parte, el propio Kant llama trascendental al conocimiento que tenemos en general, no tanto de objetos como de nuestro modo de conocerlos, en cuanto esto ha de ser posible a priori.

Igualmente, Hegel y Kant cedieron espacio a nuevas formas de pensamiento más libre para aproximar al ser humano a un concepto

(C) UNED. Revista de Derecho UNED, núm. 17, 2015 
de sujeto, tal que la propia vida pueda cambiar una forma de expresión y de conocimiento.

$\mathrm{Al}$ respecto sobre este particular, expone Irati: «En Internet, por ejemplo, cada individuo puede asumir varias identificaciones al mismo tiempo: todos pueden ser autores, agentes, productores, editores, lectores, consumidores, de manera que la subjetividad de cada papel prevalece de acuerdo con el instante. En este sentido, los papeles se mezclan y se confunden, se distancian de sus caracterizaciones tradicionales y provocan el debate acerca de la reorganización de estos temas» ${ }^{3}$.

Asimismo, la digitalización y los sistemas actuales de telecomunicación originan porfía legislativa y, consecuentemente, en los derechos de autoría tanto a nivel de propiedad intelectual como laboral.

Este esfuerzo evidencia múltiples cambios en el entorno de la propiedad intelectual y las dos, tecnología digital y propiedad, entran en conflicto por la pérdida de valor del concepto de reproducción, distribución, comunicación y control de explotación por parte del autor, que necesita poder decidir y beneficiarse de la explotación de su creación.

Admítase por el momento la tutela de los derechos de autor en las obras multimedia y particularmente los de los creadores de contenidos en plataformas e-learning al respecto como hipótesis de trabajo fundamentada en la investigación de nuevos mecanismos jurídicos eficaces; o indagar en la readaptación de los existentes, para proteger esos derechos en el espacio digital.

Como se puede inferir, es preciso el reconocimiento al autor de una obra de sus facultades para reproducirla materialmente, publicarla, adaptarla, explotarla o reivindicar su autoría, porque, solo por el hecho de ser su creador, la tiene desde ese mismo momento, incorporada a su patrimonio.

Todavía cabe señalar que una plataforma e-learning está configurada por contenidos, diseño gráfico y código fuente; pero, en relación a los contenidos, estos serán de nueva creación, preexistentes y enlazado todo ello de forma sistematizada atendiendo a los criterios del autor de la obra principal o del editor.

A su vez, los contenidos pueden estar formados por obras independientes con protección jurídica como creaciones intelectuales, aunque también pueden contener otras informaciones consideradas

${ }^{3}$ IRATI, A. «Autoría y cultura postmoderna», Consultora SciELO, 2001, págs. 92-95. 
como obras protegidas que, por su sistematización singular, constituyen una creación intelectual reconocida en el artículo 12 de la $\mathrm{LPI}^{4}$.

Por otra parte, los medios habituales para crear nuevas obras se referirán a la obra individual cuyos derechos corresponden al autor, a la colectiva en la que los derechos correspondan a la persona física o jurídica que ha tenido la iniciativa de crear la obra, coordinar el proyecto y publicarla bajo su nombre, al encargo de realización de obra en la que los derechos aparecerán designados en el contrato y, en caso de silencio, corresponderán al autor, a la realizada en colaboración, donde los derechos pertenecen a los componentes por igual, salvo pacto en contrario, y un caso a considerar en especial para el objeto de esta tesis será la obra asalariada en la que los derechos de explotación pertenecen a la empresa, excepto que se pactasen otras condiciones.

Independientemente de esto, se necesita especificar el ámbito de la cesión de derechos, porque el cambio que supone la nueva forma de transmisión de las obras intelectuales en el espacio digital y en la llamada sociedad de la información se ha debatido hacia la necesidad de redefinir los conceptos relativos a la propiedad intelectual y los derechos morales y patrimoniales del creador de la obra, para acomodarlos a las nuevas situaciones de explotación. Razón por la cual la hipótesis de trabajo plantea importantes exigencias de adaptación al derecho de propiedad intelectual por la heterogeneidad de las conceptualizaciones que integran los elementos de e-learning. Es así que el objetivo general consista en analizar los factores diferenciales y sus repercusiones entre los derechos de Propiedad Intelectual y el recono-

${ }^{4}$ Real Decreto Legislativo 1/1996, de 12 de abril, por el que se aprueba el texto refundido de la Ley de Propiedad Intelectual, «BOE» núm. 97, de 22 de abril de 1996 (Última modificación: 5 de noviembre de 2014. Referencia: «BOE»-A-1996-8930).

Artículo 12. Colecciones. Bases de datos.

1. También son objeto de propiedad intelectual, en los términos del Libro I de la presente Ley, las colecciones de obras ajenas, de datos o de otros elementos independientes como las antologías y las bases de datos que, por la selección o disposición de sus contenidos, constituyan creaciones intelectuales, sin perjuicio, en su caso, de los derechos que pudieran subsistir sobre dichos contenidos.

La protección reconocida en el presente artículo a estas colecciones se refiere únicamente a su estructura en cuanto forma de expresión de la selección o disposición de sus contenidos, no siendo extensiva a éstos.

2. A efectos de la presente Ley, y sin perjuicio de lo dispuesto en el apartado anterior, se consideran bases de datos las colecciones de obras, de datos, o de otros elementos independientes dispuestos de manera sistemática o metódica y accesibles individualmente por medios electrónicos o de otra forma.

3. La protección reconocida a las bases de datos en virtud del presente artículo no se aplicará a los programas de ordenador utilizados en la fabricación o en el funcionamiento de bases de datos accesibles por medios electrónicos. 
cimiento de autoría a los creadores de contenidos, en su esencia, de las plataformas e-learning.

Dicho lo anterior, los objetivos específicos postulan:

1. Considerar el marco normativo de los derechos de autor en el contexto histórico y la LPI.

2. Proporcionar materiales para categorizar y comparar productos integrantes del e-learning y actuar consecuentemente según la normativa aplicable.

3. Desarrollar y profundizar importantes aspectos del proceso elearning.

4. Posibilitar un adecuado uso de la síntesis de la comunicación en las obras multimedia.

5. Identificar problemas y necesidades para diseñar propuestas adecuadas y fiables.

6. Fundamentar las concepciones respecto al régimen de tutela.

7. Examinar los sistemas de seguridad y fiabilidad en las transacciones.

Consecuentemente, su estudio se establece en el desarrollo de las Tecnologías de la Información y las Comunicaciones, y el Derecho de Propiedad Intelectual como ciencia que sirve para establecer la discusión de la hipótesis en el trabajo y plantea la determinación del objeto de la propiedad intelectual una vez fijada, originando producciones audiovisuales de índole diversa.

De ahí que el derecho de autor exhibe el reconocimiento de un atributo del ser humano como creador de una obra intelectual. Acorde con esta teoría, explica Lipszic: «La inclusión del derecho de autor entre los derechos fundamentales en las constituciones nacionales, en la Declaración Universal de Derechos Humanos y en el Pacto Internacional de Derechos Económicos, Sociales y Culturales importa el reconocimiento de que se trata de un atributo inherente al ser humano y que, como tal, su protección adecuada y eficaz no puede ser desconocida. Ninguna de las disposiciones de la ley relativas a derechos conexos podrá interpretarse en menoscabo de la protección que ella otorga al derecho de autor $»^{5}$.

${ }^{5}$ LIPSZYC, D. El derecho patrimonial y las nuevas formas de explotación de las obras. Tercer Congreso Iberoamericano sobre Derecho de Autor y derechos conexos. Ed. Barreiro y Ramos S. A., Uruguay. 1997, pág. 135. 
Por esto, el cambio originado por las TIC y las nuevas obras digitales provoca el análisis de la protección jurídica en el ordenamiento de la Propiedad Intelectual por la explotación de las obras, en cuanto afecta a los derechos morales y patrimoniales de los autores.

Así, esta circunstancia justifica la imperiosa necesidad de una reforma, en corto plazo, que refuerce la protección de los derechos de autor y propiedad intelectual.

De la mano con lo anterior, se hace preciso transponer el contenido de las Directivas 2011/77/UE del Parlamento Europeo y del Consejo, de 27 de septiembre de 2011, por la que se modifica la Directiva 2006/116/CE en relación con el plazo de protección del derecho de autor y derechos afines (art. 110 bis y 119, junto a la Disposición transitoria vigésima primera del TRLPI), y Directiva 2012/28/UE del Parlamento Europeo y del Consejo, de 25 de octubre de 2012, relativa al artículo 37 bis y disposición adicional sexta y transitoria vigésima primera del TRLPI).

Estos parámetros direccionan la ley 21/2014, de 4 de noviembre, por la que se modifica el texto refundido de la Ley de Propiedad Intelectual, aprobado por Real Decreto Legislativo 1/1996, de 12 de abril, y la Ley 1/2000, de 7 de enero, de Enjuiciamiento Civil.

Estas razones sobre la necesidad de regular los problemas de los derechos de propiedad intelectual y que no deben esperar a la redacción de una nueva Ley integral sobre esta esfera han sido las justificaciones expuestas por parte del Gobierno.

En mención a lo anterior, las variaciones se establecen en tres bloques, referido el primero a la revisión del sistema de copia, cuya compensación se abona desde el 1 de enero de 2012 a cargo de los Presupuestos Generales del Estado, por lo que las entidades de gestión se encargarán de la supervisión del pago de esta composición.

Por otra parte, el segundo bloque se refiere a los mecanismos introducidos para supervisar y gestionar los derechos de Propiedad Intelectual, con nuevas funciones para las entidades de gestión y herramientas jurídicas para evitar vulneraciones en la legislación.

En cuanto al tercer bloque de las variaciones que aporta la nueva Ley 21/2014, su atención se concentra en las propias actuaciones frente a las conductas irregulares que vayan en contra de la normativa de Propiedad Intelectual.

En síntesis, este conjunto de medidas que recoge la presente ley sobre el sistema de copia privada, el diseño de dispositivos efectivos 
de verificación de las entidades de gestión de los derechos de propiedad intelectual y la mejora de las herramientas de reacción frente a las transgresiones de derechos que admita el lanzamiento de la oferta legal en el contexto digital será el objeto de cumplimentación en la exposición siguiente del artículo. Tal es el caso de las obras multimedia y, a tal efecto, las plataformas e-learning en lo que a la autoría de sus contenidos se refieren, al presentar una complejidad reunida en un mismo soporte.

\section{PROCEDIMIENTO}

Sobre las bases de las ideas expuestas, se parte del contraste del desarrollo de la creación y se formula en base al marco teórico aplicable a los derechos de Propiedad Intelectual en la Red, como problemática de investigación conceptual descriptiva. Por ello, en las características que presentan, se tiende a analizar aspectos teóricos doctrinales y normativos.

No solo analizan, sino también son inherentes a la realidad contractual y a la problemática que se está dando hoy, en un espacio globalizado y dinamizado por las tecnologías telemáticas.

Si bien es cierto que se atiende a una exploración prospectiva a través de la búsqueda que prevea condiciones sociales basadas en la aceleración de los cambios tecnológicos, con un enfoque hermenéutico comprendiendo el contexto a partir de la recogida cualitativa de información y poniendo de manifiesto, de modo patente, el estudio de los hechos y el carácter de fuente material del derecho en el que se plasman dichas innovaciones tecnológicas.

Por otra parte, esto determina la orientación del trabajo al desarrollo conceptual, inherente a las formas de contratación en plataformas e-learning y su sistematización.

A este respecto, las ideas expuestas comprenden básicamente las etapas que describe en su obra Hayman ${ }^{6}$ :

1. Documentación:

- Realizar un acopio, selección y clasificación de textos, leyes y Jurisprudencia, procurando remontarnos hasta fuentes de información primaria.

${ }^{6}$ HAYMAN, J. L. Investigación y Educación, Buenos Aires: Paidós. 1974. 
2. Análisis e interpretación de datos:

- Valorar objetivamente los conocimientos obtenidos en la recopilación y separarlos de los falsos.

- Desarrollar los conceptos generales sobre el significado de autoría y creación en la línea del tiempo.

3. Enunciado y explicación crítica:

- Comentar cada uno de los cambios propuestos en la Ley y la respuesta que otorga a la necesidad de incorporación de la Directiva CE.

- Contrastar y comparar las nuevas propuestas con la situación actual y las implicaciones que las novedades más importantes de regulación suponen al efecto.

- Describir la dimensión esencial en relación a la LPI, leyes laborales y los problemas jurídicos.

En este sentido, las TIC, a la par que la automatización de procesos, Internet y el Comercio Electrónico, han transformado la morfología del negocio en la empresa, en el contexto de la Sociedad de la Información, posibilitando la incorporación de nuevos competidores y modelos.

\section{E-LEARNING Y EMPRESA}

Se deduce un conflicto, entre el pasado y la actualidad, entre la revolución industrial y la revolución de la información, intentando solucionar esta situación; aunque, para llegar a ella, deben transcurrir unos años, y no tres o cuatro como promulgan algunos.

Por esto, la digitalización de los procesos en el mundo empresarial y su problemática reside en dichos procesos y en la gestión de los mismos.

Dicho esto, el problema no es tecnológico, ya que existe bastante tecnología, sino en contar con suficientes personas que entiendan cómo funciona su gestión.

Así, es fácil comprar por Internet; pero lo fundamental es el seguimiento de todos los procesos que llevan hasta la cumplimentación del pedido.

Para tal efecto, la empresa se compone de empleados, clientes inversores y proveedores. 
Pero, sobre estos cuatro pilares, hay que configurar la digitalización de la empresa, sabiendo que en lo que más se ha invertido ha sido en la planificación de recursos empresariales que afectan a los departamentos de logística, producción y distribución.

Es verdad que últimamente también se ha invertido en atención al cliente y marketing.

Asimismo, con Internet aparecen los portales y la gestión de la cadena de suministro.

Por tanto, el objetivo es digitalizar la producción desde el principio al final, con el fin de conseguir que formen parte del sistema reduciendo costes y creando nuevas versiones de gestión seguras.

Todo esto parece confirmar que la protección de la creación de obras intelectuales será una solución por las características propias de estas nuevas producciones humanas en la Red.

A pesar de que existen contradicciones sobre las ventajas de la educación a distancia, considerando el avance de las tecnologías en la red, se podría decir que la enseñanza con soporte TIC reporta una interacción a todos los niveles, la flexibilidad y adaptabilidad de metodologías y sistemas de evaluación, costes más reducidos y acotados que en la enseñanza presencial, replicabilidad de los procesos, integración de la información a cualquier nivel educativo o administrativo, favoreciendo de este modo la coordinación y participación de equipos multidisciplinares.

Aún así, conviene señalar las debilidades que se le atribuyen como tal soporte TIC, entre las que destaca la desconfianza en su efectividad, el diferente nivel de socialización del alumnado y la elevada tasa de abandono.

Acorde con lo expuesto, sostiene Cabero: «Las Nuevas Tecnologías se diferencian de las tradicionales, no en lo que se refiere a su aplicación como medio de enseñanza, sino en la posibilidad de creación de nuevos entornos comunicativos y expresivos que facilitan a los receptores la posibilidad de desarrollar nuevas experiencias formativas, expresivas y educativas» ${ }^{7}$

En definitiva, el proceso de mejora de una plataforma e-learning requiere un estudio riguroso y una investigación que propicie nuevas

${ }^{7}$ CABERO ALMENARA, J. Las nuevas tecnologías de la información y la comunicación: aportaciones a la Enseñanza. Nuevas Tecnologías Aplicadas a la Educación, Síntesis educación, Madrid, 2001. 
formas de enseñar y aprender con las tecnologías de que se dispone y aquellas que surjan como fruto de esa investigación.

Desde hace casi veinticinco años, el concepto de e-learning se ha dispersado en el mundo de las TIC con diferentes acepciones, y así, en la hipótesis de la Tesis, se mantiene el carácter complejo y plural al mismo tiempo que no existe una definición concluyente.

De igual modo que se analizó la aplicación didáctica de las plataformas y en especial la plataforma de e-learning, se verificará su relación con la empresa.

Así que, para llegar a este desarrollo, será precisa la exposición de los diferentes conceptos sobre e-learning, como la propuesta por García Peñalvo y Seoane Pardo: «Desde una perspectiva de la calidad se puede definir e-Learning como un proceso de enseñanza/aprendizaje, orientado a la adquisición de una serie de competencias y destrezas por parte del alumno, caracterizado por el uso de las tecnologías basadas en web, la secuenciación de unos contenidos estructurados según estrategias preestablecidas a la vez que flexibles, la interacción con la red de estudiantes y tutores y unos mecanismos adecuados de evaluación, tanto del aprendizaje resultante como de la intervención formativa en su conjunto, en un ambiente de trabajo colaborativo de presencialidad diferida en espacio y tiempo, y enriquecido por un conjunto de servicios de valor añadido que la tecnología puede aportar para lograr la máxima interacción, garantizando así la más alta calidad en el proceso de enseñanza/aprendizaje» ${ }^{8}$.

\section{III.1 Comercialización E-Learning}

Las TIC, a la par que la automatización de procesos, Internet y el comercio electrónico han transformado la morfología del negocio en la empresa, en el contexto de la Sociedad de la Información, posibilitando la incorporación de nuevos competidores y modelos de negocio.

Por su parte, en la actualidad, el problema de la comercialización en el mundo de la red está controvertido y su relación con un comer-

${ }^{8}$ SEOANE PARDO, A. M. y GARCÍA PEÑALVO, F. J. (2006). «Factores de calidad en el eLearning aplicado a la formación continua: el diploma Tutor online de la Universidad de Salamanca y el Espacio Europeo de Educación Superior (EEES)». En Simposio Internacional de Informática Educativa (8..$^{\circ}$ 2006. León, España), L. Panizo Alonso et al. (Eds.), «8th International Symposium on Computers in Education: proceedings: october 24-26th, León, Spain» (pp. 425-432). León: Universidad de León. 
cio electrónico en apogeo lleva a la dicotomía entre la seguridad en la transacción o emisión y los derechos de propiedad intelectual que asisten al autor con su implicación laboral.

Según el estudio, amplía dentro de este mercado electrónico toda una serie de novedades mediáticas a los autores para la accesibilidad de sus obras y, consiguientemente, un nuevo horizonte de explotación en la dirección de un mercado electrónico flexible y eficiente que facilite la integración de las creaciones de dichos autores y su protección en la RED.

Dentro de ese marco, los desafíos de la economía y los sucesos relacionados con la seguridad de los sistemas de información se propició afrontarlos con el máximo acervo.

Simultáneamente, la seguridad al utilizar el Comercio Electrónico como medio habitual de transacción y la delimitación de los alcances y contenidos que se derivan de su relación con el derecho han sido motivo de análisis por lo que conlleva con respecto a la seguridad de las implicaciones actuales del trabajo del autor en la red. Es así que este planteamiento en el trabajo que no debemos ignorar, sino más bien controlar, por lo que su realización significa sobre la transmisión global y la titularidad de los autores objeto de la Tesis.

Por lo tanto, se piensa que la unión de la transacción electrónica y la seguridad en la misma constituyen el fundamento de la costumbre en su uso cotidiano por las empresas y los particulares, lo que la sitúa en el punto de mira de juristas, ya que la tecnología no es indiferente a los sistemas de construcción social, incluidas las ciencias jurídicas, por ser una cuestión relevante que necesita una reflexión acerca de la norma y sus fundamentos axiológicos, fundamentalmente en las tecnologías de la información como instrumento esencial de la comunicación, transmisión y acercamiento al entendimiento.

Considerando el entendimiento como la suprema facultad cognitiva del ser humano y como potencia se determina por su objeto, lo que hace necesario preguntarse por el objeto del entendimiento humano para conocer su operación cognitiva.

Vinculado al concepto, el profesor Millán Pueyes expone sobre las facultades superiores del hombre: "Ya se hizo constar en su momento que, a diferencia del animal, el hombre es capaz de aprehender los medios como medios, lo que equivale a decir que el hombre no solamente puede conocer las cosas que son medios, sino también, precisamente, darse cuenta de que esos medios lo son. Lo que distingue al hombre del animal es así, en este punto, la capacidad que el hombre 
tiene de conocer que el medio es medio, lo que a su vez implica, en general, que el hombre tiene la facultad de conocer el «ser». A esta facultad es a lo que se llama entendimiento, y por disponer de ella el hombre no se limita a la captación de las formas corpóreas concretas y singulares, sino que también puede extenderse a las formas corpóreas abstractas y, en general, a todo cuanto es»?.

Por esta razón, el derecho y la sociedad interactúan, es decir, que la tecnología no es indiferente a los sistemas de construcción social como las ciencias jurídicas, originan una interrelación con la lingüística, la sociología, la pedagogía, la estadística y en particular la comunicación.

En este caso, se considera la comunicación como un proceso social en la conducta humana en el que se establece una relación espacio-temporal entre el emisor, el canal y el receptor, constituyendo un proceso de manifestación del pensamiento mediante símbolos.

Así, la comunicación, como facultad, tendrá entre sus funciones ser el vehículo primario que refleje simultáneamente la personalidad del individuo y la cultura de la sociedad, haciendo posible su transmisión y continuidad.

Consecuentemente, la información como concepto delimita la implicación del contenido en un proceso de comunicación.

Por lo que se refiere al influjo de la voluntad y el entendimiento, el profesor Millán Pueyes postula: «El entendimiento mueve a la voluntad proponiéndole el fin, determinando su objeto. La voluntad, en cambio, puede mover al entendimiento en lo que toca a la aplicación de éste a su actividad. El influjo del entendimiento consiste, pues, en especificar la voluntad; el de ella, en impulsar al entendimiento. Y no puede ocurrir de otra manera, pues ni el entendimiento quiere, ni la voluntad entiende. Querer es una operación cuyo objeto es extrínseco a la facultad volitiva, mientras que entender es una cierta posesión cuyo objeto es intrínseco a la facultad intelectiva» ${ }^{10}$.

Sobre una definición del comercio electrónico, nos podríamos encontrar con suficientes acuñaciones resolutivas cada una por su parte.

Así, la Directiva comunitaria enuncia la materia básica que compone el comercio electrónico y destaca la contratación, la responsabilidad civil de los intermediarios, las comunicaciones comerciales y la prestación de servicios en línea.

${ }^{9}$ MILLÁN PUEYES, A. Fundamentos de Filosofía, Arial, Madrid 1968, pág. 357-358.

${ }^{10}$ MILLÁN, A. Op. cit., pág. 375. 
De este modo, la característica conceptual de este nuevo comercio, radica en su carácter electrónico, que se sustancia en la transmisión de datos a través de redes de comunicación, como Internet y similares.

Igualmente, podría realizarse una primera definición de Comercio Electrónico al considerarlo como una prestación de bienes o servicios remunerada, en el que las partes se encuentran a distancia y es llevada por medios electrónicos, necesitando un marco jurídico acorde a las necesidades y sensibilizando a consumidores y empresas en relación a las ventajas que reporta y al mismo tiempo eliminando las incertidumbres y falta de confianza por las razones ya expuestas.

Con todo, el Comercio Electrónico puede definirse como el intercambio de bienes y servicios a través de Internet, como una tecnología que permite tener acceso a información comercial y realizar transacciones electrónicas en forma sencilla y económica.

Se puede sintetizar en que el comercio electrónico, virtual, informático o cibercomercio prevé en la utilización de elementos electrónicos, que, de forma directa o indirecta, puedan incidir en la formación de la voluntad, en el intercambio de bienes y servicios, transacciones o actividades de naturaleza comercial, por medio de redes cerradas o abiertas.

En cualquier caso, el Comercio Electrónico se presenta como un factor esencial, según los especialistas, del crecimiento económico y el mundo de la enseñanza, a pesar de que necesita un marco jurídico claro y flexible.

\section{III.2 Perspectivas en las plataformas E-Learning}

Los usuarios de formación a través de plataformas digitales, personas con distintos niveles y características personales observarán evoluciones en las aplicaciones e-learning, durante este año 2015, en relación a la automatización, interacción y diseño.

Dado que herramientas informáticas dedicadas al análisis y gestión de datos voluminosos, como el Big Data, la contribución al estímulo del conocimiento por la praxis del juego, con la Gamificación y el aprendizaje aumentado (augmented learning) con los servicios multimedia interactivos con contenidos automatizados conllevarán la creación de cursos online abiertos (Mooc's Corporativos), que reflejarán la evolución del modelo procedimental para la formación y la 
asunción de un prototipo de aprendizaje fundamentado en las heterogéneas modalidades.

Además, se verán mejoradas las gestiones e-learning y su eficacia sobre las plataformas virtuales, con una interfaz de programación de aplicaciones (API) en relación a los cambios de contraseñas, boletines informativos, interactividad y mensajes personalizados.

Por otra parte, la aplicación de un diseño Web Responsive ofrece más flexibilidad, permitiendo desarrollar páginas que se visualicen de forma correcta en cualquier dispositivo y resolución ya que al utilizar CSS3 media queries, como un tipo de medio, permitirán que la presentación del contenido se adapte a un rango específico de dispositivos de salida, sin tener que cambiar el contenido en sí, que con un layout o dispositivo con imágenes flexibles detectaría desde que medio accede el alumno.

En consecuencia, le permitirá conectarse desde cualquiera de los terminales posibles a su plataforma formativa, porque sería válida para todos, en vez de construir una website para cada uno.

Se debe agregar que la técnica del Story Learning (Storyteling), fundamentada en el dinámico y didáctico método de "flashforward» o alteración de secuencias temporales y lógicas para incentivar y reforzar la evaluación y reflexión del usuario, junto con los LMS, o sistemas de gestión de aprendizaje electrónico, en la nube contribuirán, igualmente que los anteriores, a planificar creativa y eficazmente los nuevos diseños de plataformas e-learning y sus contenidos en los próximos tiempos.

Este esfuerzo pondrá imprescindiblemente a disposición de usuarios e-learning, como premisa fundamental de las plataformas y herramientas de autoría, medios para la adaptación de contenidos de formación online a los nuevos multidispositivos, desarrollando cursos, en la última versión de 29 de octubre del 2014, de HTML5, revisión del lenguaje fundamental de la WWW, y que detalla dos variantes de sintaxis desarrolladas en paralelo para HTML la variante conocida como HTML5 y otra como XHTML5.

De acuerdo con este desarrollo en plataformas de autoría que procura solo un diseño de contenidos multidispositivos potenciadores del gobierno de notables cantidades de datos, disminuyendo el tiempo de carga y mejorando el posicionamiento de páginas web que admiten mayores elementos gráficos y multimedia, se garantizaría la adaptabilidad de los contenidos a los diversos terminales, facilitando la for- 
mación al disponer los usuarios, los medios necesarios para la adquisición efectiva de conocimientos.

Los resultados de estos avances están a la vista con el abandono por parte de YouTube, en el pasado mes de enero, de Flash, para incorporar HTML5, y el impulso de Google de HTML5Rocks.com, igualmente que el lanzamiento de HTML5 Resource Center por parte de Facebook y un número considerable como Apple, SAP y demás líderes que lo favorecen en sus plataformas.

Atendiendo a estas consideraciones, las comparaciones competen también al currículo de la naturaleza del receptor y su entorno de aprendizaje, como asimismo al aspecto procedimental y de soportes técnicos para observar y establecer diferencias en cuanto a su estructura.

Al comparar estas evidencias, estará fundamentada en una experiencia concreta acorde con el objeto de estudio, una observación reflexiva que provoque la conceptualización abstracta, motor de la experimentación activa, como aplicación de los conocimientos adquiridos a través de las herramientas propias de la plataforma digital testada y diseñada académica, técnica y gráficamente por un equipo de expertos técnicos, pedagogos, diseñadores, editorialistas y coordinadores de producción.

En este sentido, se resalta la necesidad de identificar al usuario con el modelo de plataforma a diseñar y las herramientas adecuadas a incorporar según el modelo de aprendizaje y la importancia de los contenidos, de acuerdo con la flexibilización de la formación para acomodarse, desde las plataformas e-learning a las necesidades crecientemente diversificadas por medio de una disponibilidad generalizada de las nuevas tecnologías interactivas que se concretan en el desarrollo de originales modelos pedagógicos, dotados de herramientas de hardware y software que refuerzan la comunicación personal, grupal y tutorial.

Sobre las bases de las ideas expuestas, Internet como medio para la comunicación e interactuación conforma espacios sincrónicos y asincrónicos incorporados en las plataformas e-learning asistiendo la información, distribución, búsqueda y recuperación de materiales en cualquier formato digital establecido según unas premisas de configuración creadas y orientadas a la economía del lenguaje y su uso.

Vinculado al concepto, es preciso impulsar por medio de aplicaciones telemáticas la calidad de la comunicación y la formación digi- 
tal como estilo aglutinador de las posibilidades tecnológicas de enseñanza, fundamentadas en un sistema mediador de comunicación virtual.

En virtud de esto, el aprendizaje corporativo como tecnología pedagógica utilizada en el e-learning precisa compartir unos objetivos comunes por parte de un equipo interdisciplinar para que su diseño resulte efectivo.

\section{CONCLUSIONES}

Siendo, pues, la pretensión principal del trabajo ahondar en el conocimiento de las razones que justifican la regulación jurídica y el reconocimiento natural del derecho de autor a partir del análisis histórico, ha llegado el momento, una vez analizados los procesos legales, de llegar a algunas conclusiones o ideas que justifiquen los merecimientos, que, por naturaleza y sentido del derecho, les corresponden en el marco de la propiedad intelectual.

Más importante que las diferencias son las coincidencias que se observan en las diversas constituciones, tratados internacionales y normas de derechos humanos con respecto a la propiedad intelectual y su tutela jurídica como aspecto fundamental del progreso y la cultura, y sobre todo del derecho de autoría.

En efecto, una primera conclusión derivada de esta evolución histórica del derecho de autoría es que sólo el interés de la sociedad conlleva una solución jurídica, ya que la dificultad estriba en el interés económico de los sujetos que incorporan una nueva industria, la cual lleva a regular los intereses de los autores para obtener unos beneficios económicos en detrimento de los sociales y patrimoniales que les corresponden.

No obstante, puesto que el problema de la vulneración de estos derechos aumenta de forma amenazante cada vez más para los creadores de contenidos en plataformas digitales, autores en definitiva de su obra original, como contempla el artículo $1 .^{\circ}$ de la Ley de Propiedad Intelectual 23/2006, referente de nuestra hipótesis sobre el derecho de autoría plena por mor de su creatividad personal, plantea diversas consideraciones:

1. Las obras son el resultado de un proceso de creación y de investigación del autor, que le confieren; por este hecho, derechos morales y patrimoniales respetados por los ciudadanos y protegidos por el estado. 
Por la implicación que este derecho de autor tiene tanto en la creación y la investigación como en la economía de los países es necesaria la adopción de medidas contra su vulneración, ya que el derecho de autor no protege las ideas per se, sino sus formas de expresión, tanto literarias como científicas o artísticas, como es el tema que nos ocupa, estimulando la creatividad intelectual para la difusión de contenidos e-learning.

Por consiguiente, el reconocimiento del derecho de autor como cualidad del ser humano, creador de obras del intelecto, tanto de índole patrimonial como espiritual y expresión de la personalidad en su creación, origina el derecho de autoría que le es intrínseco, porque nace con su persona.

Parece lógico, tal como se expone en el desarrollo legislativo, que la propiedad intelectual debe evolucionar, para lo que no son suficientes unas primeras modificaciones, sino que será necesario ir evolucionando cara al reconocimiento de los derechos que la creación, originalidad, y buen hacer merecen estos creadores.

De este modo, es coherente que los autores se centren hoy en día no sólo en la aplicación de medidas directas por violación de derechos, sino, fundamentalmente, en la adopción de medidas que consoliden los derechos que hoy se les niegan de forma definitiva, aunque se le reconozcan de manera afín.

De acuerdo con las ideas expuestas, se desprenden unas conclusiones significativas, para comprender el significado de la propiedad intelectual en el entramado social y particularmente en el de la creación de contenidos para plataformas e-learning.

Así, el avance tecnológico originó cambios fundamentales en la estructuración del conocimiento y la organización de la sociedad, desde que emerge el cuerpo solo, que, separado de la afectividad y de la inteligencia, es una abstracción, un pensamiento vacío, un espectro intelectual.

De acuerdo con este sentido, todo movimiento y actitud es necesariamente la expresión del ser entero, el resultado de un pensamiento, consciente o inconsciente, o los dos a la vez.

Por tanto, el cuerpo es el primer medio de percepción y de expresión, el primer medio de comunicación con otro ser humano, el que prepara y precede otras formas de comunicación, particularmente el lenguaje. 
En efecto, el cuerpo es el medio de comunicación más auténtico y profundo; pero, para que esto suceda, hay que dejarle la posibilidad de expresarse para que pueda establecerse la comunicación.

Como resultado, la creación humana implica una idea de descubrimiento, en el sentido de que en el beneficio resultante del acto creador podrían descubrirse datos no previstos en el proyecto de la creación.

En consecuencia, toda creación implica un descubrimiento, una puesta de manifiesto de algo que ontológicamente estaba presente en la realidad, el lenguaje, hasta la digitalización provocando un desarrollo, una transferencia y una aplicación a la sociedad, por su interactividad, automatización y diversidad.

Además, el conocimiento, como intransferible y personal, implica información integrada en la estructura cognitiva del individuo, por lo que no se puede confundir un término con el otro, como se produce habitualmente.

De ahí su importancia en el mundo de la educación por su interactividad y la deslocalización que define la aplicación e-learning, deshaciendo la unidad de tiempo, espacio y presencia, en beneficio de un sistema de aprendizaje y docencia más global, comprometido y competitivo por medio del aula virtual.

Así pues, los educadores desarrollarán contenidos propios para esta enseñanza digital con las repercusiones de autoría que afrontan y objeto de este estudio, esbozo de la Tesis en curso.

Dentro de este marco, esto es significativo porque en torno a esta nueva visión de la enseñanza se ha instalado una industria y un mercado que, en algunos casos, conlleva, en el espacio laboral, un conflicto de intereses necesitado de una tutela judicial eficiente.

Más aún, el impacto de las tecnologías y el desarrollo de nuevas sociedades propician la clarificación de los derechos de propiedad intelectual de los trabajadores como la imposibilidad de registrar una obra por parte del empresario, sin adquirir previamente los derechos sobre la misma.

Si bien es cierto que existen presunciones y excepciones legales, se hace necesario que dichas circunstancias aparezcan formuladas como cesión de derechos en el contrato laboral y no operen de facto, como es habitual.

Atendiendo a estas consideraciones, las relaciones laborales en el entorno de la Propiedad Intelectual se regirán por la propia normati- 
va al amparo del artículo 51 del TRLPI (Real Decreto Legislativo $1 / 1996$ de 12 de abril) ${ }^{11}$.

En este sentido, la cesión de derechos se regula privadamente y en exclusiva para la actividad habitual del empresario e-learning y siempre con el carácter temporal de dos años en el caso de España.

En todo caso, se considera claramente el carácter intransmisible de los derechos morales del autor sobre su reconocimiento siempre, como tal de su obra.

${ }^{11}$ Artículo 51. Transmisión de los derechos del autor asalariado.

1. La transmisión al empresario de los derechos de explotación de la obra creada en virtud de una relación laboral se regirá por lo pactado en el contrato, debiendo éste realizarse por escrito.

2. A falta de pacto escrito, se presumirá que los derechos de explotación han sido cedidos en exclusiva y con el alcance necesario para el ejercicio de la actividad habitual del empresario en el momento de la entrega de la obra realizada en virtud de dicha relación laboral.

3. En ningún caso podrá el empresario utilizar la obra o disponer de ella para un sentido o fines diferentes de los que se derivan de lo establecido en los dos apartados anteriores.

4. Las demás disposiciones de esta Ley serán, en lo pertinente, de aplicación a estas transmisiones, siempre que así se derive de la finalidad y objeto del contrato.

5. La titularidad de los derechos sobre un programa de ordenador creado por un trabajador asalariado en el ejercicio de sus funciones o siguiendo las instrucciones de su empresario se regirá por lo previsto en el apartado 4 del artículo 97 de esta Ley. 